\title{
Mioepitelioma pré-auricular: revisão de literatura e relato de caso
}

\author{
Myoepithelioma preauricular: literature review and case report
}

\author{
Alessandra Kuhn-Dall'Magro* \\ Aline Bruinsma** \\ Jonathan Rodrigo Lauxen ${ }^{* *}$ \\ Renato dos Santos ${ }^{* *}$ \\ Eduardo Dall'Magro ${ }^{* * * *}$
}

\section{Resumo}

Objetivo: este trabalho visa demonstrar, por meio de relato de caso e revisão de literatura, o comportamento do mioepitelioma benigno. Considerado um tumor raro das glândulas salivares, possui crescimento lento, muitas vezes assintomático, cuja incidência é praticamente igual entre os sexos, podendo ter ligeira predileção pelas mulheres. Pode ocorrer em várias faixas etárias, sendo mais comum por volta dos 50 anos. A glândula parótida e o palato são os locais de predileção desse tumor que pode variar de 1 a $5 \mathrm{~cm}$, geralmente encapsulado, indolor, bem delimitado, e com coloração esbranquiçada. O principal diagnóstico diferencial do mioepitelioma é o adenoma pleomórfico. Histologicamente, o mioepitelioma benigno é composto por células mioepiteliais e o tratamento constitui-se de remoção cirúrgica da lesão com baixa taxa de recidiva após sua remoção completa. Relato de caso: este trabalho relatou um caso clínico de mioepitelioma benigno localizado em região pré-auricular, removido cirurgicamente e acompanhado por oito anos, sem sinais de recidiva, bem como as características clínicas e microscópicas dessa enfermidade. Considerações finais: embora raros, tumores como o mioepitelioma podem ser encontrados nas avaliações clínicas de rotina. Cabe ao cirurgião- dentista realizar uma inspeção completa da face do paciente, compreendendo todo o sistema estomatognático e as estruturas adjacentes dentro dos critérios da semiologia. Quanto mais precoce o diagnóstico dessas patologias, melhor o seu prognóstico de tratamento.

Palavras-chave: Mioepitelioma. Pré-auricular. Glândulas salivares.

\section{Introdução}

Mioepitelioma é uma neoplasia benigna rara de tecidos moles, que afeta glândulas salivares, tem origem a partir de células mioepiteliais, que são ectodérmicas, derivadas das células contráteis e rotineiramente identificadas em muitos tecidos normais com função secretora ${ }^{1,2}$.

Diversos estudos descreveram que a predileção do tumor, quando afeta glândulas maiores, é a glândula parótida, porém quando afeta glândulas menores, a predileção é pelas glândulas da região do palato ${ }^{1-4}$. Os tumores de parótida são raros, e representam $3 \%$ de todos os tumores de cabeça e pescoço, $1,6 \%$ de todos os tumores benignos das glândulas salivares maiores e $0,6 \%$ dos tumores de todo o organismo ${ }^{5}$. O mioepitelioma benigno representa cerca de $1 \%$ dos tumores de glândulas salivares ${ }^{6}$.

A incidência do mioepitelioma é praticamente igual entre os sexos, apresentando uma discreta predileção pelo sexo feminino $0^{4-7}$. Esse tumor pode ocorrer em qualquer idade entre seis e $81 \operatorname{anos}^{7,8}$, porém, a faixa etária mais comum é próxima aos 50 $\operatorname{anos}^{4,9}$. As neoplasias de glândulas salivares apresentam incidência anual de um para 100.000 indivíduos $^{7}$, sendo que a maioria dos mioepiteliomas são benignos e apenas $10 \%$ são malignos ${ }^{10}$.

Considerando o mioepitelioma como um tumor que se caracteriza clinicamente por ausência de linfoadenopatia e de dor, com coloração normal da

Especialista em CTBMF, Santa Casa, Porto Alegre, Mestre em Ciências Médicas - UFRGS, professora dos Cursos de Pós Graduação em CTBMF do Ceom (Centro de Estudos Odontológicos Meridional) - Passo Fundo e do IOA (Instituto Odontológico das Américas) - Balneário Camboriú-SC; Membro do Corpo Clínico do Hospital São Vicente de Paulo de Passo Fundo (HSVP) e do IOT (Instituto de Ortopedia e Traumatologia), Passo Fundo-RS, Brasil.

Cirurgião-dentista graduado pela Faculdade de Odontologia da Universidade de Passo Fundo (UPF), Passo Fundo-RS, Brasil.

Cirurgião-dentista graduado pela Faculdade de Odontologia da Universidade de Passo
Aluno do Curso de Especialização em CTBMF- Ceom - HSVP, Passo Fundo-RS, Brasil.

Especialista em Prótese Dentária - USP, Mestre em Laser em Odontologia (Lelo) - USP, Mestre e Doutor em Materiais Dentários - Unicamp, professor titular III da Faculdade de Odontologia da UPF, Passo Fundo-RS, Brasil. 
mucosa, sem formação de úlceras e/ou paralisação do nervo facial. Uma das únicas queixas do paciente que leva a procura de atendimento é o aumento de volume da região, causando muitas vezes assimetria facial ou dificuldade de deglutição e fonação ${ }^{1-9}$. Quanto às suas características macroscópicas, o tumor é descrito por alguns autores como de crescimento lento, que pode variar de 1 a $5 \mathrm{~cm}$, de coloração esbranquiçada, geralmente encapsulado e bem delimitado ${ }^{4,6}$, e por outros como um tumor bem circunscrito, de coloração marrom-amarelada, superfície brilhante e lisa e sem envolvimento ósseo ou de tecidos moles adjacentes ${ }^{9}$. Microscopicamente, é caracterizado por apresentar uma variada morfologia celular, com células em padrão fusiforme, plasmocitóide, epitelióide ou clara ${ }^{3}$. O tumor, que é composto por células mioepiteliais, pode possuir até $5 \%$ de células epiteliais ductais como normal ${ }^{6,8}$ e caracteriza-se por um crescimento sólido tubular, que consiste normalmente em um grupo de células epiteliais internas com citoplasma eosinófilo e outro grupo de células mioepiteliais externas com citoplasma claro ${ }^{1}$. Quando o tumor é do tipo plasmocitóide, esse se comporta de forma benigna, enquanto, células fusiformes ou células claras estão presentes em muitos casos malignos, devido à sua atividade proliferativa ${ }^{9}$ Quanto às características imuno-histoquímicas, o principal marcador imuno-histoquímico do mioepitelioma é a proteína S-100, muitas vezes, o diagnóstico do tumor depende da positividade dessa proteína ${ }^{4}$.

Ter conhecimento das patologias, bem como diferencia-las, é indispensável para o diagnóstico correto. $\mathrm{O}$ principal diagnóstico diferencial do mioepitelioma é o adenoma pleomórfico ${ }^{4}$ que irá se diferenciar do mioepitelioma por exibir componente ductal, considerando que nesse é aceita a presença de até $5 \%$ de componentes ductais como normal ${ }^{3,5}$. Outro diagnóstico diferencial é o mioepitelioma maligno, o qual depende do tipo de célula predominante ${ }^{11-13}$ e se apresenta com algumas características sugestivas de malignidade, como, pleomorfismo celular, aumento da atividade mitótica, atipia citológica, focos de necrose e invasão tecidual.

O tratamento sugerido nos estudos revisados é a excisão cirúrgica completa com pequena margem de segurança. A radioterapia não é considerada um tratamento corriqueiro, pois é utilizada quando a cirurgia não é considerada viável, por exemplo, em tumores que apresentam diâmetro superior a $4 \mathrm{~cm}$, estágio mais elevado e de alto grau neoplásico, ou quando se tem dificuldade de delinear margem cirúrgica ${ }^{1,6,9,11-13}$.

O mioepitelioma benigno apresenta baixa taxa de recorrência, desde que a excisão cirúrgica seja completa. Quando ocorre a ruptura da cápsula durante a ressecção cirúrgica e a presença de margens microscópicas positivas a taxa de recorrências aumenta $^{2,6,8,12,13}$.
O objetivo deste trabalho é realizar uma revisão de literatura bem como um relato de caso de um mioepitelioma localizado na região pré-auricular esquerda adjacente à glândula parótida.

\section{Materiais e método}

A pesquisa bibliográfica deste trabalho foi realizada nos bancos de dados: Pub Med, BVS, Lilacs, Portal Capes - Periódicos, Scielo e periódicos impressos, com período de busca de 1995 a 2013. Nas bases de dados, utilizamos as palavras-chave: mioepitelioma, mioepitelioma de glândula salivar e mioepitelioma benigno. Foi relatado o caso clínico de um paciente com tumor benigno de células mioepiteliais (mioepitelioma), o qual foi removido cirurgicamente no Hospital São Vicente de Paulo e encaminhado para exame histopatológico. Este estudo apresenta o relato de acompanhamento pós-cirúrgico, e termo de consentimento livre e esclarecido aprovado pelo comitê de ética do Hospital São Vicente de Paulo.

\section{Relato do caso}

Paciente do sexo masculino, 29 anos, branco, procurou atendimento na Especialidade de Cirurgia e Traumatologia Buco-Maxilo-Facial do Ambulatório de Especialidades do SUS do Hospital São Vicente de Paulo de Passo Fundo - RS apresentando uma lesão pré-auricular no lado esquerdo da face, com aproximadamente seis meses de evolução. $\mathrm{O}$ paciente era assintomático, cuja queixa era uma leve assimetria facial. Foram solicitados exames séricos, radiográficos e uma tomografia computadorizada (Figura 1) no intuito de planejar o tratamento cirúrgico.

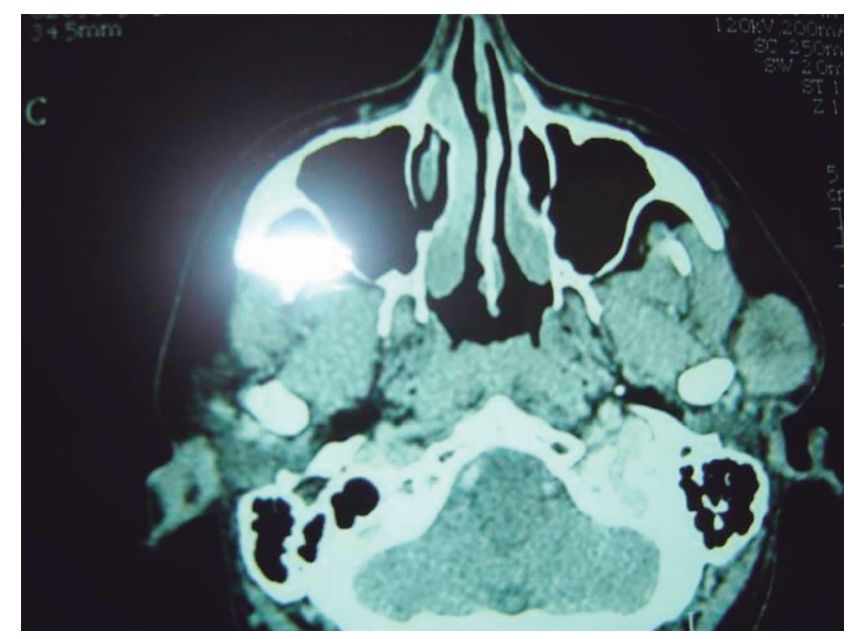

Figura 1 - Imagem tomográfica da lesão, na região pré-auricular esquerda, corte axial

A partir desses exames, foi realizada biópsia incisional da lesão, confirmando o diagnóstico de mioepitelioma. O exame anatomopatológico revelou 
uma estrutura nodular constituída por tecido conjuntivo fibroso hialinizado com cordões celulares constituídos por células de citoplasma claro, vacuolizado e células de aspecto epitelial, de citoplasma eosinófilo, agrupadas em pequenos cordões sólidos (Figura 2).

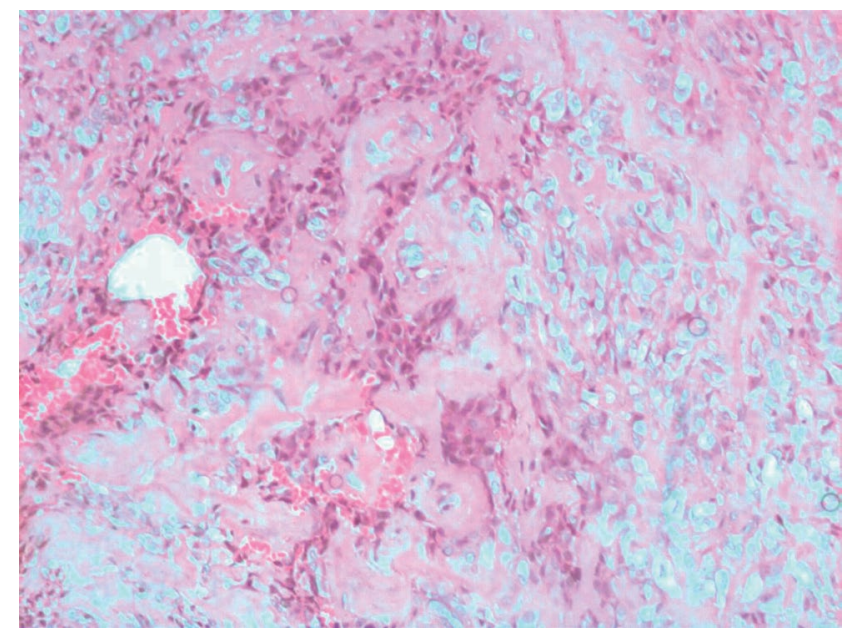

Figura 2 - Exame histopatológico: Células fusiformes em estroma fibromixoide.

Coloração: Hematoxilina e Eosina (aumento 50x).

O exame imuno-histoquímico revelou células neoplásicas exibindo imunorreação com anticorpos anti-Pankeratina, anti-EMA e anti-S100, não mostrando positividade com os anticorpos anti-Actina, anti-HMB45, anti-Desmina e anti-CD34.

A partir da confirmação diagnóstica, planejou-se a exérese total da lesão, sob anestesia geral, por meio de acesso pré-auricular (Figura 3) e dissecação tecidual no intuito de separar a lesão e principalmente, preservar tanto a glândula parótida esquerda, quanto o nervo facial.

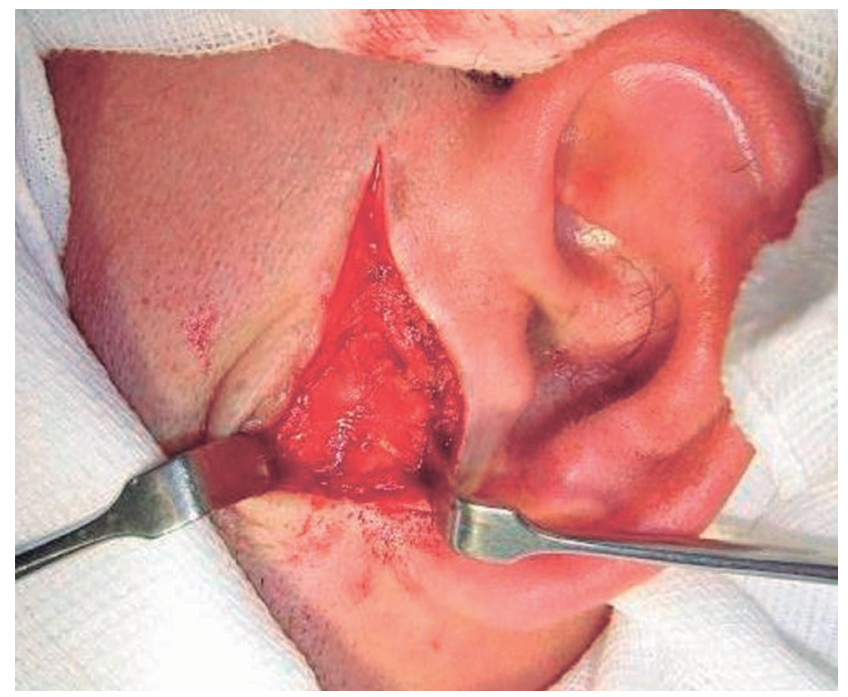

Figura 3 - Incisão pré-auricular e dissecação

A lesão foi completamente removida (Figura 4), em seis segmentos teciduais irregulares, medindo entre $0,7 \times 0,5 \times 0,5 \mathrm{~cm}$ e 3,5x3x2 cm de diâmetro (Figura 5), de cor pardo-amarelados, lobulados e elásti- cos, em que o segmento maior apresentou lesão nodular parda e elástica de $2,5 \times 2 \times 1,5 \mathrm{~cm}$. Foi também removido um linfonodo da região, e encaminhado para exames anatomopatológicos, não apresentando sinais de metástase. A cirurgia ocorreu sem intercorrências. Houve confirmação diagnóstica de mioepitelioma e o exame microscópico revelou que todos os fragmentos teciduais estavam infiltrados por tecido neoplásico constituído por ninhos ou cordões de células poligonais ou fusiformes, de núcleos ovóides, hipercromáticos e com diminutos nucléolos, bem como, áreas fibrohialinizadas.

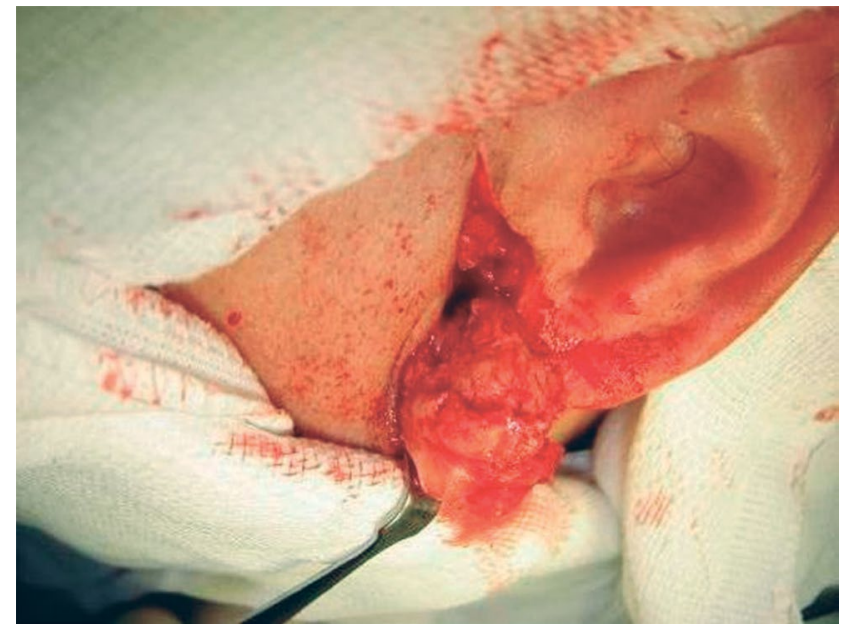

Figura 4 - Exérese total da lesão

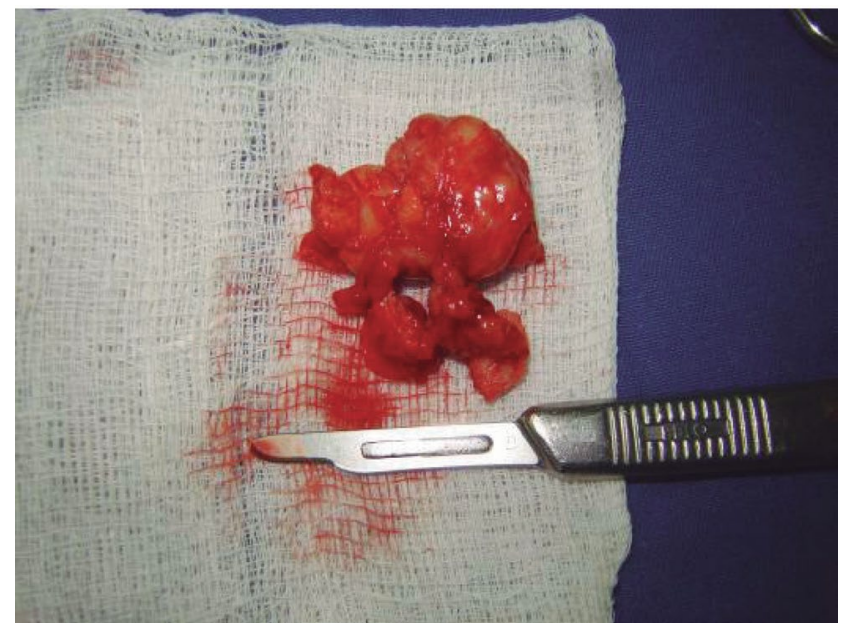

Figura 5 - Peça cirúrgica encaminhada para exame anatomopatológico e imuno-histoquímico

Realizou-se sutura, com nove pontos simples, removidos dez dias após o procedimento cirúrgico, com o tecido apresentando boa cicatrização (Figura 6). 


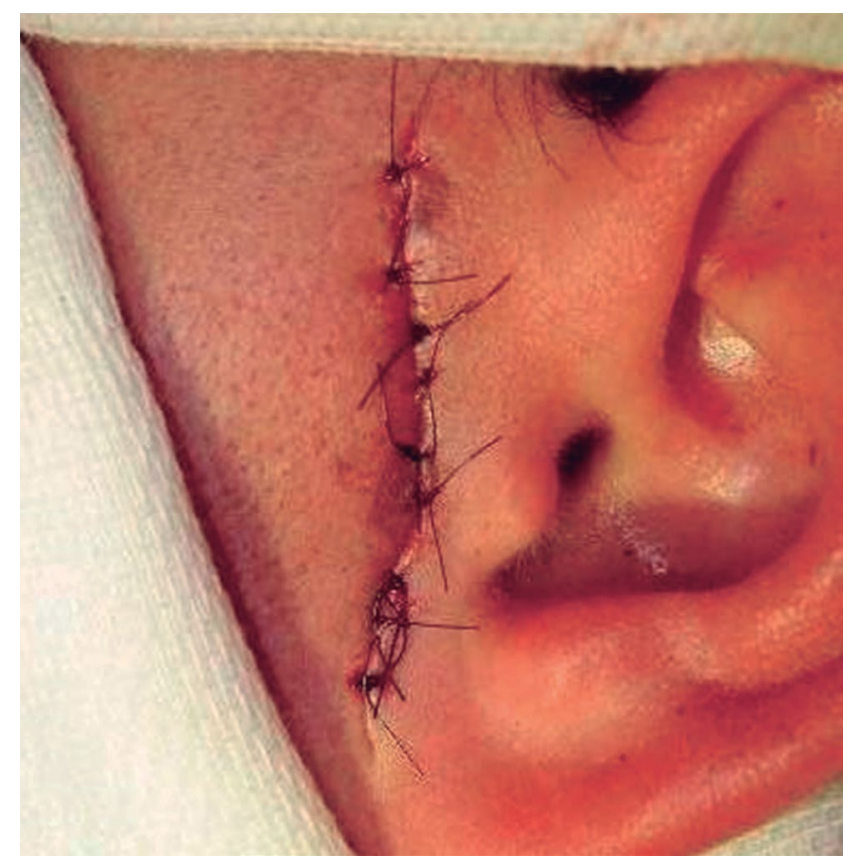

Figura 6 - Sutura da pele, após remoção da lesão

O diagnóstico de mioepitelioma foi novamente confirmado (Figura 7). O paciente segue sob acompanhamento há oito anos sem apresentar recidivas da lesão até o momento.

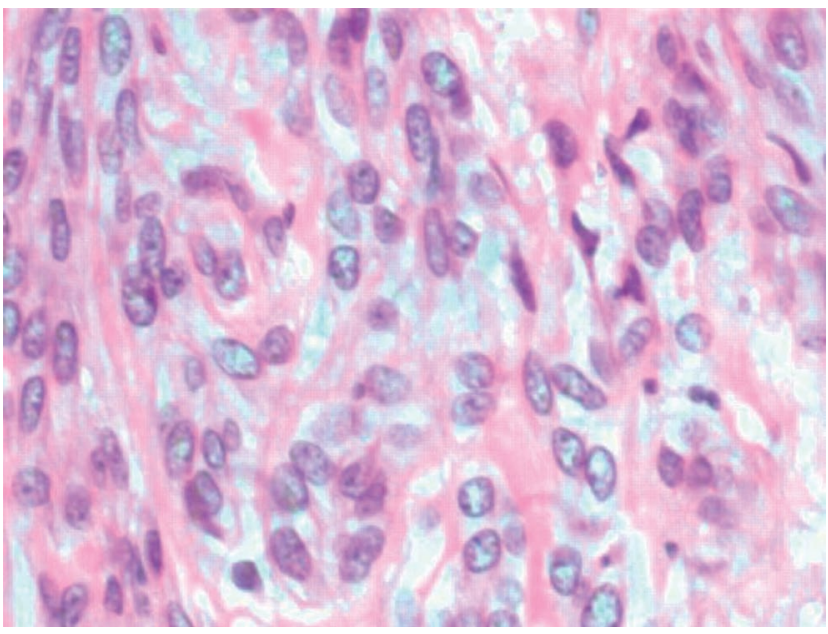

Figura 7 - Células fusiformes agrupadas e distribuídas em várias direções, de núcleos excêntricos. Coloração: Hematoxilina e Eosina (aumento: 200x).

\section{Discussão}

O mioepitelioma é uma neoplasia epitelial de baixo grau de malignidade, na qual a glândula parótida é o sítio anatômico mais relatado ${ }^{2,4,12-15}$. Estudos revelam que os tumores da parótida são raros e representam apenas $3 \%$ de todos os tumores de cabeça e pescoço, $1,6 \%$ de todos os tumores benignos das glândulas salivares maiores, e $0,6 \%$ dos tumores de todo o organismo ${ }^{5}$. Clinicamente, o edema localizado e bem delimitado é o único sinal da lesão ${ }^{1}$. Esse estudo relata o caso de um paciente assintomático, com queixa de leve assimetria facial no lado esquerdo, na região pré-auricular. Foi realizada biópsia incisional e o resultado dos exames anatomopatológicos e imuno-histoquímicos confirmaram o diagnóstico.

O exame imuno-histoquímico revelou que as células neoplásicas exibiram imunorreação com anticorpos anti-Pankeratina (marcador de citoqueratina em células de origem epitelial), anti-EMA (marcador de celulas de origem epitelial, particularmente glandular) e anti-S100 (marcador de proteína S-100), não mostrando positividade com os anticorpos anti-Actina (marcador de actina sarcomérica), anti-HMB45 (marcador específico de melanoma), anti-Desmina (marcador de desmina sarcomérica em músculo liso ou estriado) e anti-CD34 (apresenta afinidade pelo endotélio vascular), a partir de relatos encontrados na literatura, os marcadores típicos de células mioepiteliais claras são actina, proteína S-100 e vimentina $0,8^{6}$, bem como CK $14^{13}$ (marcador de queratina-14), histologicamente, o mioepitelioma benigno é composto por células mioepiteliais e se aceita a presença de até $5 \%$ de células epiteliais ductais como normal, enquanto maior número de formações ductais direciona-os para o diagnóstico de tumor misto ${ }^{6}$.

O exame microscópico realizado a partir da biópsia e da exérese da lesão mostrou estrutura nodular constituída por tecido conjuntivo fibroso hialinizado, entre o qual se observou ninhos ou cordões celulares poligonais ou fusiformes constituídos por células de citoplasma claro, núcleos ovoides, hipercromáticos e com diminutos nucléolos, e células de aspecto epitelial. Diante desses achados, os autores acreditam que todos os tipos morfológicos das células constituintes dos mioepiteliomas representam células da linhagem mioepitelial. Em estágios bastante variados de sua evolução, a morfologia celular desse tumor é variada, apresentando células em padrão fusiforme, plasmocitóide, epitelióide ou clara $^{3,4,8}$. A partir disso, conclui-se que as técnicas estruturais, os marcadores histoquímicos e os imuno-histoquímicos utilizados são ferramentas úteis que diferenciam mioepitelioma de outros tumores benignos e malignos nas glândulas salivares ${ }^{5}$. O principal marcador imuno-histoquímico do mioepitelioma é a proteína S-100, geralmente, o diagnóstico depende da positividade do exame para essa proteína ${ }^{4}$, diferindo do adenoma pleomórfico por não exibir componente ductal ${ }^{3}$.

Mioepiteliomas benignos devem ser removidos além dos limites do tumor, se for realizada ressecção completa, as recorrências são raras ${ }^{4,6,10}$. Biologicamente, mioepiteliomas são benignos, na maioria dos casos, mas ocasionalmente podem se infiltrar localmente e sofrer metástase, passando a ser considerados malignos ${ }^{6,12,13}$. Nesse caso clínico, não houve crescimento infiltrativo, nem áreas de necrose, e no exame histológico as células apresentaram-se bem diferenciadas, descartando-se a possibilidade de malignidade.

Apesar das características de neoplasia benigna que o tumor apresenta, as recidivas ocorrem em quase $20 \%$ dos $\operatorname{casos}^{15,16}$, o que exige acompanha- 
mento em longo prazo. Esse paciente, no entanto, não apresentou qualquer sinal de recidiva durante os oito anos de acompanhamento.

\section{Considerações finais}

Embora raros, tumores como o mioepitelioma podem ser encontrados nas avaliações clínicas de rotina. Cabe ao cirurgião-dentista realizar uma inspeção completa da face do paciente compreendendo todo o sistema estomatognático e estruturas adjacentes dentro dos critérios da semiologia. Quanto mais precoce o diagnóstico dessas patologias, melhor o seu prognóstico de tratamento.

\section{Abstract}

Objective: this work allow to demonstrate by case report and literature review the comportment of benign myoepithelioma. It is considered a rare tumor of the salivary glands, of slow growth, and often asymptomatic, whose incidence is nearly equal between the sexes, may have a slight predilection for women. It can occur in all age groups, being more common around 50 years. The parotid gland and palate are the sites of predilection of this tumor. It can vary from 1 to $5 \mathrm{~cm}$, generally being encapsulated, painless and well delimited, with coloring whitish. The main differential diagnosis of myoepithelioma is the pleomorphic adenoma. Histologically, benign myoepithelioma is composed of myoepithelial cells and treatment consists of surgical removal of the lesion with low rate of recurrence after complete removal. Case report: this work reported a case of benign myoepithelioma located in the preauricular region, removed surgically and followed for eight years without signs of recurrence, as well as the clinical and microscopic characteristics of this disease. Final considerations: although rare, tumors like myoepithelioma can happen in rotine evaluations. Dentists need improve a complete inspection of patient face including all stomatognatic system as soon as adjacent structures by rich semiology criterion. How more precoce the pathology diagnosis more better the prognosis.

Keywords: Myoepithelioma. Pre-auricular. Salivary glands.

\section{Referências}

1. Hunt KT, Stevens MR, Abdelsayed RA, Nguyen CT. Benign myoepithelioma of floor of mouth with mandibular involvement: a case report and literature review. J Oral Maxillofac Surg 2011; 69(12):3001-5.

2. Silveira EJD, Pereira ALA, Fontoura MC, Souza LB, Freitas RA. Mioepitelioma de glândula salivar menor: uma análise imunohistoquímica de quatro casos. Rev Bras Otorrinolaringol 2006; 72(4):528-32.

3. Das DK, Haji BE, Ahmed MS, Hossain MN. Myoepithelioma of the parotid gland initially diagnosed by fine needle aspiration cytology and immunocytochemistry: a case report. Acta Cytol 2005; 49(1):65-70.
4. Lee MW, Nam SY, Choi HJ, Choi JH, Moon KC, Koh JK. Myoepithelioma of parotid gland presenting as infra-auricular subcutaneous mass. J Cutan Pathol 2005; 32(3):240-4.

5. Simpson RHW, Jones H, Beasley A. Benign myoepithelioma of the salivary glands: a true entity? Histopathol 1995; 27:1-9.

6. Takai Y, Dardick I, Mackay A, Burford-Mason A, Mori M. Diagnostic criteria for neoplastic myoepitelial cells in pleomorphic adenomas and myoepitheliomas. Immunohistochemical detection of muscle-specific actin, cytokeratin 14, vimentin and glial fibrillary protein. Oral Surg Oral Med Oral Pathol Oral Radiol Endod 1995; 79:330-41.

7. Dardick I. Myoepithelioma: definitions and diagnostic criteria. Ultrastruct Pathol 1995; 19:335-45

8. Ávila RE, Samar ME, Fonseca I. Mioepitelioma de parótida: estúdio histológico, histoquímico e inmunohistoquímico. Iniciacón a la investigación. Rev Eletrônica 2008; 3(4):1-8.

9. Ostrosky A, Villa DM, Federico JK. Mioepitelioma benigno: presentación de un caso clínico. Rev Española de Cirugía Oral y Maxilofacial 2007; 29(5):336-41.

10. Junior AT, Almeida OP, Kowalski LP. Parotid neoplasms: analysis of 600 patients attended at a single Institution. Braz J Otorhinol 2009; 75(4):497-501.

11. Astarci HM, Celik A, Sungu N. Cystic clear cell myoepithelioma of the parotid gland. A case report. Oral Maxillofac Surg 2009; 13:45-8.

12. Sperandio FF, Giudice FS, Pinto-Junior DS. Myoepithelioma of the Soft Palate: a case report giving special attention to the differential diagnosis. J Oral Maxillofac Res 2011; 2(1):1-5.

13. Cardesa A, Alos L. Myoepithelioma. In: Barnes L, Eveson JW, Reichart P, Sidransky D. World Health Organizartion Classification of Tumors. Pathology and Genetics of Head and Neck Tumors. Lyon: IARC Press 2005; 259-60.

14. Hornick JL, Fletcher CD. Myoepithelial tumors of soft tissue: a clinical pathologic and immunohistochemical study of 101 cases with evaluation of prognostic parameters. Am J Surg Pathol 2003; 27(9):1183-96.

15. Gun BD, Ozdamar SO, Uzun L. Salivary gland myoepithelioma with focal capsular invasion. Ear Nose Throat Journal 2009; 88(7):1005-9.

16. Kadlub N, Galiani E, Frailag S, Sabah Boudjema, Marie-Paule Vazquez, Coulomb A, et al. Soft Tissue Myoepithelioma of the Scalp in a 11-Year-Old Girl: A Challenging Diagnosis. Pediatric Dermatol 2012; 29(3):345-8.

\section{Endereço para correspondência:}

Alessandra Kuhn-Dall'Magro

Rua Teixeira Soares, 777/02 e 301 - Centro

99010-080 Passo Fundo-RS

Fone: +555436010723

E-mail: alessandrakuhn@hotmail.com

Recebido: 03/11/2013. Aceito: 06/08/2014. 